\title{
DESEMPENHO EM SEMEADURA TARDIA DE VINTE HÍBRIDOS DE MILHO EM AREIA QUARTZOSA DO CERRADO DO TRIÂNGULO MINEIRO
}

\author{
Renato de Mello Prado ${ }^{1}$ \\ Luiz Ricardo Goulart Filho ${ }^{2}$
}

\section{RESUMO}

Tendo como objetivo de avaliar desempenho de híbridos de milho em semeadura tardia, em Areia Quartzosa de baixa fertilidade do cerrado do Triângulo Mineiro, instalou-se um experimento com vinte híbridos de milho: IR 4332, RA 200, IR 4334, IR 4335, RA 100, IR 4347, IR 4348, IR 5206, IR 5321, IR 5335, IR 5336, IR 5407, IR 5408, IR 30, Z8452, XL 380, P3210, DINA 170, CMS 50, BR 201, no mês de janeiro, na Fazenda Experimental Água Limpa da Universidade Federal de Uberlândia. $\mathrm{Na}$ ocasião do florescimento da cultura avaliou-se incidência de Phaeosphaeria maydis e na colheita a produtividade, número de espiga por planta, peso médio de espiga, peso de grãos por espiga e porcentagem de sabugo da espiga e de plantas eretas. Concluiu-se que os híbridos DINA 170, XL 380 e RA200 apresentaram melhor desempenho na produtividade atingindo incrementos de $22,9 \%, 17,9 \%$ e $9,7 \%$ respectivamente comparada com a testemunha da região BR 201, enquanto o IR 5206 sofreu redução de $24,4 \%$. Os híbridos avaliados apresentaram baixa ou média incidência de Phaeosphaeria com exceção dada ao IR 4335. Portanto a escolha do híbrido adaptado mostrou-se ferramenta importante "a custo

Doutorando, Faculdade de Ciências Agrárias e Veterinárias/UNESP, Via de Acesso Prof. Paulo Donato Castellane s/n. CEP 14870-000, Jaboticabal-SP, E-mail: rmprado@fcav. unesp.br

2 Prof. Ph.D, Universidade Federal de Uberlândia, Caixa Postal 593, CEP 38400-000, Uberlândia-MG, Brasil. 
zero" para garantir aumento da produtividade em solo arenoso de cerrado, de baixa fertilidade, semeado tardiamente.

Palavras-chave: milho, híbridos, semeadura tardia, Areia Quartzosa, região dos cerrados.

\section{ABSTRACT}

\section{PERFORMANCE OF 20 CORN HYBRIDS, PLANTED UNDER CONDITIONS OF LATE SOWING IN QUARTZIPSAMMENT OF THE SAVANA OF THE TRIANGULO MINEIRO}

In the aim of assessing the performance of corn hybrids planted under conditions of late sowing in quartzose low fertily sand of the savana of the Triangulo Mineiro, na experiment was conducted in january with 20 corn hybrids, at the Experimental Farm Água Limpa of the Universidade Federal de Uberlândia: IR 4332, RA 200, IR 4334, IR 4335, RA 100, IR 4347, IR 4348, IR 5206, IR 5321, IR 5335, IR 5336, IR 5407, IR 5408, IR 30, Z 8452, XL 380, P3210, DINA 170, CMS 50, BR 201. At the time of blooming the incidence of phasphaeria maydis was assessed, and at harvest time na evaluation was made of yield, quantity of ears per plant, average weight per ear, weight of grains per ear and percentage of corncobs and erect plants. It was found that the hybrids DINA 170, XL 380 and RA 200 showed the best yield with productivity gains of $22,9 \%$, $17,9 \%$ and $9,7 \%$, respectively, as compared to the control of region BR 201, whereas IR 5206 suffered a productivity loss of $24,4 \%$. The hybrids evaluated showed low or medium incidence of phaeosphaeria, except for IR 4335. Therefore, the choice of the adapted hybrid planted under conditions of late sowing proved to be na import "zero cost" tool for guaranteeing an increase of yield in the sandy low fertility soil of the savanna.

Key words: corn, hybrids, late sowing, quartzipsamment, savanna region 


\section{INTRODUÇÃO}

No contexto mundial, a produção brasileira de milho ocupa o terceiro lugar, depois das dos Estados Unidos e da China (Oliveira, 1992).

A principal fronteira agrícola mundial para produção de milho continua sendo o cerrado brasileiro, que abrange 207 milhões de hectares do País (Macedo, 1996).

Apesar do conhecido potencial agrícola do cerrado, a produtividade nacional do milho ainda é baixa, por diversos fatores, desde a baixa fertilidade do solo, ao stand desuniforme, manejo inadequado de plantas daninhas e pragas, baixa adubação nitrogenada, compactação do solo, uso de híbridos pouco adaptados, entre outros fatores.

Apesar de todos os fatores de produção serem importantes para a produtividade do milho, segundo Magalhães \& Paiva (1993) o uso de híbridos adaptados é uma das poucas formas de conseguir acréscimo de produção sem custo adicional.

$\mathrm{Na}$ última década a agricultura, e particularmente o cultivo do milho, vem sofrendo transformações profundas com a globalização da economia, passando a exigir do lavrador maior eficiência na produção agrícola. Assim, o uso de híbridos de milho regionais adequados passa a ser obrigatório para garantir a máxima produtividade econômica.

Com o objetivo de testar, em comparação com os cultivares locais, o potencial genético de materiais introduzidos, bem como de selecionar e recomendar cultivares de maior potencial produtivo e boa adaptação às condições locais, vêm sendo instalados ensaios regionais de competição de híbridos de milho em solos de baixa e média fertilidade, desde 1977 (Oliveira, 1982).

Normalmente existem duas épocas definidas para semeadura do milho no Brasil Central, a de verão, de outubro a dezembro, a qual coincide com o início da época das águas, e a de safrinha, de março e abril, aproveitando o final do período chuvoso. Entretanto, na região dos cerra- 
dos, em função do predomínio de grandes propriedades agrícolas aliado ao número limitado de dias úteis de trabalho das semeadoras e às irregularidades do início das chuvas, ocorre normalmente atraso da semeadura de verão, avançando no mês de janeiro, o que caracteriza a terceira época, dita de semeadura tardia.

São escassos os ensaios de competição de híbridos de milho conduzidos na região dos cerrados do Triângulo Mineiro, na época da semeadura tardia, pois a maioria desses experimentos a semeadura ocorre preferencialmente no período de outubro à primeira quinzena de dezembro. Deste modo, objetivou-se avaliar o desempenho de vinte híbridos de mitho em semeadura tardia, quanto à produtividade e a alguns de seus componentes, em Areia Quartzosa de baixa fertilidade, na região do Triângulo Mineiro.

\section{MATERIAL E MÉTODOS}

O ensaio foi conduzido na Fazenda Experimental Água Limpa pertencente à Universidade Federal de Uberlândia, município de Uberlândia-MG, em Areia Quartzosa álica (Embrapa, 1982) de baixa fertilidade cuja análise química, conforme as descrições da EMBRAPA (1979), apresentou $\mathrm{pH}$ (água) $=5,5 ; \mathrm{Al}=0 ; \mathrm{Ca}=6,0 ; \mathrm{Mg}=4,0 ; \mathrm{H}+\mathrm{Al}=21$; $\mathrm{CTC}=32 \mathrm{mmol}_{\mathrm{c}} \mathrm{dm}^{-3} ; \mathrm{P}$ (Mehlich) $=0,4 \mathrm{e} \mathrm{K}=20 \mathrm{mg} \mathrm{kg}^{-1} \mathrm{e} \mathrm{MO}=10 \mathrm{~g} \mathrm{~kg}^{-1}$. A análise física revelou classe textural arenosa, com as seguintes características granulométricas expressa $\mathrm{em} \mathrm{k} \mathrm{kg}^{-1}$ : areia grossa $=250$; areia fin $\mathrm{a}=570$; silte $=30$ e argila $=150$, obtidas pelo método da pipeta (Embrapa, 1979).

O sistema de preparo do solo foi convencional: uma gradagem pesada e outra leve, às vésperas da semeadura, para nivelamento da área. Em seguida realizou-se a sulcagem a $10 \mathrm{~cm}$ de profundidade, com cultivador, em espaçamento de $\left.0,{ }^{n}\right) \mathrm{m}$ entre linhas. No fundo do sulco aplicou-se adubação de base com $300 \mathrm{~kg}$ da fórmula 4-30-16 + 0,2\% Zn por hectare, de acordo com a COMISSÃ̃ DE FERTILIDADE DE MINAS GERAIS (1989). Em seguida foi realizada a semeadura dos híbri- 
dos de milho, em 14 de janeiro de 1995, objetivando atingir 49.000 plantas por hectare.

A adubação de cobertura constou de $90 \mathrm{~kg}$ de $\mathrm{N} \mathrm{ha}^{-1}$ e $75 \mathrm{~kg}$ de $\mathrm{K}_{2} \mathrm{O}_{\text {ha-1 }}$, sendo $50 \mathrm{~kg}$ de $\mathrm{N}$ ha-1 e o total do $\mathrm{K}_{2} \mathrm{O}$ aos 25 dias após a emergência e restante do $\mathrm{N}\left(40 \mathrm{~kg} \mathrm{ha}^{-1}\right)$ aos 45 dias após a emergência das plantas.

O controle de plantas daninhas foi realizado por capina manual, no período crítico de competição, ou seja, dos 20 aos 45 dias após a semeadura da cultura.

Usaram-se quatro blocos ao acaso, com parcelas de quatro fileiras de $5 \mathrm{~m}$ de comprimento, espaçadas de $0,90 \mathrm{~m}$. A parcela útil constou das duas linhas centrais, com $9,0 \mathrm{~m}^{2}$.

Em pleno florescimento da cultura, foram atribuídas notas para estimar nível de incidência de doença foliar (Phaeosphaeria maydis) utilizando-se a seguinte escala: 1- Nenhuma mancha na parcela; 2- Umas manchas em poucas folhas da parcela; 3-Algumas manchas em poucas folhas da parcela; 4- Algumas manchas na maioria das plantas da parcela; 5-Manchas na maioria das plantas da parcela; 6- Manchas em todas ou quase todas as plantas da parcela; 7 - Bastante manchas em todas ou quase todas as plantas da parcela; 8- Muitas manchas em todas ou quase todas as plantas da parcela; 9- Secagem parcial ou total das plantas da parcela.

A colheita foi realizada quando os grãos apresentaram teor de umidade inferior a $0,2 \mathrm{~kg} \mathrm{~kg}^{-1}$. No entanto para obtenção dos parâmetros de produtividade a umidade dos grãos foi corrigida para $0,13 \mathrm{~kg} \mathrm{~kg}^{-1}$ pelo método da estufa a alta temperatura constante $\left(105^{\circ} \mathrm{C}\right)$.

Desta forma obtiveram-se os seguintes parâmetros: produtividade, número de espiga por planta, peso médio de espiga, peso de grãos por espiga e porcentagem de sabugo da espiga e de plantas eretas.

A análise estatística dos resultados foi realizada através do teste de $\mathrm{F}$ para detecção de diferenças entre tratamentos. As comparações entre as médias foram realizadas pelo teste de Duncan a $5 \%$ de probabilidade (Pimentel-Gomes, 1990). 


\section{RESULTADOS E DISCUSSÃO}

Durante o desenvolvimento da cultura constatou-se que a precipitação foi favorável nos períodos críticos de exigência hídrica da cultura, desde a fase de desenvolvimento vegetativo (janeiro e fevereiro), no florescimento e enchimento de grãos (março). Nos meses de janeiro, fevereiro, março, abril e maio, a precipitação em $\mathrm{mm}$ foi de 390, 151, 342, 35 e 45 respectivamente. Portanto a semeadura tardia em janeiro não apresentou restrição hídrica para o desenvolvimento da cultura, na região.

A produtividade média do ensaio $\left(3314 \mathrm{~kg} \mathrm{ha}^{-1}\right)$ foi baixa, embora maior que a média nacional, talvez por excesso de chuva, que ocorreu da primeira à terceira semana após emergência das plantas, propiciando maior lixiviação de nitrogênio e potássio, pois se trata de solo arenoso $\left(140 \mathrm{~g} \mathrm{~kg}^{-1}\right.$ de argila). Isto reduziu a disponibilidade nas fases de maior demanda da planta por tais nutrientes. Outro fator, que era esperado, seria a baixa fertilidade do solo, notadamente em $\mathrm{Ca}, \mathrm{Mg}, \mathrm{P}, \mathrm{K}$ e $\mathrm{MO}$ e a própria semeadura tardia, pois Silva et al. (1996) observaram que semeadura tardia em dezembro causou redução média de $46,7 \%$ na produtividade de três híbridos de milho, comparada à semeadura em agosto. A redução da produção do milho pela semeadura tardia é explicada pelas alterações no ciclo da planta em função basicamente da temperatura e da luminosidade (Pereira \& Cruz, 1993).

Para o parâmetro produtividade, como era de esperar, houve diferença significativa entre os híbridos nas condições deste ambiente ou seja em semeadura tardia e em solo arenoso de baixa fertilidade. Fato semelhante também foi relatado por Eberhart \& Russel (1966).

Especificamente, os híbridos DNA 170 (4294 kg ha-1), XL 380 $\left(4035 \mathrm{~kg} \mathrm{ha}^{-1}\right)$ e RA200 (3666,75 $\left.\mathrm{kgha}^{-1}\right)$ foram os que apresentaram melhor desempenho, sem diferir entre si, quanto a produtividade, atingindo incrementos da ordem de $22,9 \%, 17,9 \%$ e $9,7 \%$ comparados à testemunha da região BR 201 (3312,25 $\left.\mathrm{kg} \mathrm{ha}^{-1}\right)$, enquanto que o híbrido IR 5206 $\left(2663,50 \mathrm{~kg} \mathrm{ha}^{-1}\right)$ foi o menos responsivo, sofrendo uma redução de $24,4 \%$ (Tabela 1). Portanto estes resultados estão de acordo com Magalhães \& 
Paiva (1993) que salientam ser possível o aumento da produtividade do milho apenas com uso de híbrido mais adaptado ao dado ambiente.

Para o número médio de espigas por planta, houve diferença significativa, sendo que o XL $380(1,21)$ e o IR $5336(1,19)$ foram superiores, seguidos dos híbridos IR 30 e do IR 4348, ambos com 1,03 (Tabela 1).

Quanto aos parâmetros peso médio de espiga e peso de grãos por espiga, o híbrido DINA 170 destacou-se, porém, de maneira geral, observou-se que os híbridos mais produtivos apresentaram tais variáveis da espiga com valores também maiores (Tabela 1).

Esperava-se que os híbridos mais produtivos apresentassem menor porcentagem de sabuco na espiga, o que não ocorreu, haja vista que o híbrido XL 380, um dos mais produtivos, apresentou maior porcentagem de sabugo, atingindo $24,51 \%$. No caso do híbrido XL 380 , o que garantiu boa produtividade, mesmo com maior porcentagem de sabugo da espiga, foi o número de espigas por planta, citado anteriormente. Observa-se ainda que $Z 8452$ apresentou menor porcentagem de sabugo, com 19,36\% (Tabela 1).

Quanto a porcentagem de plantas eretas, observou-se quase 90\%, ou $10 \%$ de acamamento ou quebramento dos colmos de milho para o híbrido IR 4347, diferindo significativamente dos demais híbridos, exceto para os híbridos IR 5408, IR 4332, IR 4334 e IR 5407, que apresentaram acamamento ou quebramento aproximado de $5 \%$ (Tabela 2). Portanto os híbridos que apresentarem acamamento ou quebramento igual ou superior a $5 \%$ não devem ser recomendados, por esta característica influenciar a colheita mecânica e, consequentemente, a produtividade.

Houve diferença significativa para o nível de incidência de Phaeosphaeria, como era de se esperar, pelos diferentes tipos de híbridos presentes no ensaio, concordando com Paccola-Meirelles et al. (1998), aos quais observaram variações na incidência desta doença nos 79 híbridos de milho avaliados. 
Tabela 1. Resultados médios obtidos de produtividade, $n^{\circ}$.de espigas/ planta, peso médio de espiga, peso de grãos por espiga e porcentagem de sabugo em vinte híbridos de milho em semeadura tardia no Cerrado do Triângulo Mineiro.

\begin{tabular}{|c|c|c|c|c|c|}
\hline Tratamentos & $\begin{array}{l}\text { Produtividade } \\
\qquad\left(\mathrm{kg} \mathrm{ha}^{-1}\right)\end{array}$ & $\begin{array}{l}\mathrm{N}^{\circ} \text {. de } \\
\text { espigas/ } \\
\text { planta }\end{array}$ & $\begin{array}{c}\text { Peso } \\
\text { médio } \\
\text { de espiga } \\
\text { (g) }\end{array}$ & $\begin{array}{c}\text { Peso de } \\
\text { gräos/ espiga } \\
\text { (g) }\end{array}$ & $\begin{array}{l}\text { Porcentagem } \\
\text { de sabugo }\end{array}$ \\
\hline DINA 170 & $4294,25 a^{4}$ & $0,99 \mathrm{c}$ & 111,43 a & $86,66 \mathrm{a}$ & 21,92 abcdef \\
\hline XL 380 & $4035,75 a b$ & $1,21 \mathrm{a}$ & $84,11 \mathrm{~b}$ & $63,58 \mathrm{~b}$ & $24,51 \mathrm{a} \quad 0$ \\
\hline RA 200 & $3666,75 a b c$ & $0,99 \mathrm{c}$ & $91,95 a b$ & $72,56 a b$ & 21,04 bcdef \\
\hline IR 5408 & $3622,75 a b c$ & $0,96 \mathrm{c}$ & $92,49 a b$ & $74,81 \mathrm{ab}$ & 19,38 ef \\
\hline IR 3 & $3619,00 \mathrm{abc}$ & $1,03 \mathrm{bc}$ & $86,93 a b$ & $68,14 a b$ & 21,43 abcdef \\
\hline IR 5336 & $358,50 \mathrm{aboc}^{\circ} \mathrm{c}$ & $1,19 a b$ & $74,70 \mathrm{~b}$ & $59,74 \mathrm{~b}$ & 20,12 def \\
\hline IR5321 & $3576,50 \mathrm{abc}$ & $1,00 \mathrm{c}$ & $89,49 a b$ & $68,48 a b$ & $23,56 a b c$ \\
\hline Z 8452 & $3500,25 \mathrm{abc}$ & $0,98 \mathrm{c}$ & $87,30 a b$ & $70,31 a b$ & $19,36 \mathrm{f}$ \\
\hline BR 201 & $3312,25 a b c$ & $0,98 \mathrm{c}$ & $83,13 b$ & $65,24 \mathrm{~b}$ & 21,49 abcdef \\
\hline RA 100 & $3280,50 \mathrm{abc}$ & $1,00 \mathrm{c}$ & $82,49 \mathrm{~b}$ & $63,91 \mathrm{~b}$ & 22,52 abcdef \\
\hline IR 43 & $3261,75 a b c$ & $1,03 b c$ & $78,15 \mathrm{~b}$ & $60,55 \mathrm{~b}$ & 22,37 abcdef \\
\hline CMS 50 & $3159,00 a b c$ & $0,96 \mathrm{c}$ & $79,72 \mathrm{~b}$ & $63,65 \mathrm{~b}$ & 20,21 def \\
\hline IR 4335 & $3150,00 \mathrm{abc}$ & $1,00 \mathrm{c}$ & $78,90 \mathrm{~b}$ & $61,36 \mathrm{~b}$ & 22,36 abcdef \\
\hline IR 4332 & $3063,00 \mathrm{abc}$ & $0,98 \mathrm{c}$ & $77,52 \mathrm{~b}$ & $60,71 b$ & 21,60 abcdef \\
\hline IR 4347 & 3041,25 bc & $0,96 \mathrm{c}$ & $78,97 \mathrm{~b}$ & $61,98 b$ & 21,49 abcdef \\
\hline IR 4 & 2959,00 bc & $0,99 \mathrm{c}$ & $74,61 \mathrm{~b}$ & $57,89 \mathrm{~b}$ & 22,63 abcde \\
\hline P 3210 & $2862,75 \mathrm{bc}$ & $0,99 \mathrm{c}$ & $71,71 \mathrm{~b}$ & $55,46 \mathrm{~b}$ & $22 ; 74 \mathrm{abcd}$ \\
\hline IR 5407 & 2829,25 bc & $0,99 \mathrm{c}$ & $72,54 \mathrm{~b}$ & $55,47 \cdot \mathrm{b}$ & $23,50 \mathrm{abc}$ \\
\hline IR 5335 & 2809,75 bc & $0,98 \mathrm{c}$ & $73,55 b$ & $55,86 \mathrm{~b}$ & $24,27 a b$ \\
\hline IR 5206 & $2663,50 \mathrm{c}$ & $0,91 \mathrm{c}$ & $73,00 \mathrm{~b}$ & $57.99 \mathrm{~b}$ & 20,50 cdef \\
\hline Média & 3314,79 & 1,00 & 82,12 & 64,22 & 21,85 \\
\hline $\mathrm{CV}$ & $22,11 \%$ & $10,74 \%$ & $19,04 \%$ & $19,27 \%$ & $8,78 \%$ \\
\hline
\end{tabular}

Médias seguidas da mesma letra na vertical não diferem entre si pelo teste de Duncan a $5 \%$ de probabilidade.

Os híbridos avaliados apresentaram baixa (notas de 1 a 3,5) ou média (notas 3,6 a 5,0) incidência de Phaeosphaeria com exceção dada ao IR 4335 com alta incidência da doença (notas de 5,1 a 9) (Tabela 2). Entretanto era de se esperar maior número de híbridos no nível médio e alto de incidência da phaeosphaeria, pelo fato da semeadura tardia adotado no presente ensaio, haja vista que na literatura indica que semeadura tardia do milho predispõem a cultura a ter maior incidência de phaeosphaeria (Pegoraro et al., 1998). 
Tabela 2. Resultados médios obtidos da porcentagem de plantas eretas e da incidência da Phaeosphaeria maydis em vinte híbridos de milho em semeadura tardia no Cerrado do Triângulo Mineiro.

\begin{tabular}{|c|c|c|c|}
\hline \multirow[t]{2}{*}{ Tratamentos } & \multirow[t]{2}{*}{$\begin{array}{c}\text { Porcentagem de plantas } \\
\text { eretas }\end{array}$} & \multicolumn{2}{|c|}{$\begin{array}{l}\text { Incidência média da } \\
\text { Phaeosphaeria maydis }\end{array}$} \\
\hline & & Notas $^{2}$ & Nível $^{3}$ \\
\hline IR 4335 & $100,00 a^{1}$ & $6,00 \mathrm{a}$ & Alto \\
\hline IR 5335 & $98,86 a b$ & $5,00 a b$ & Médio \\
\hline DINA 170 & $98,84 a b$ & $5,00 a b$ & Médio \\
\hline BR 201 & $99,43 a b$ & $5,00 a b$ & Médio \\
\hline IR 4348 & $98,29 a b$ & $4,75 a b$ & Médio \\
\hline IR 4334 & $95,45 \mathrm{abc}$ & $4,25 a b$ & Médio \\
\hline IR 5407 & $95,45 \mathrm{abc}$ & $4,25 a b$ & Médio \\
\hline IR 5408 & 95,39 bc & $4,00 a b$ & Médio \\
\hline IR 30 & $98,86 a b$ & $4,00 a b$ & Médio \\
\hline IR 4332 & $96,02 \mathrm{abc}$ & $3,75 a b$ & - Médio \\
\hline RA 200 & $97,73 a b$ & $3,75 a b$ & Médio \\
\hline RA 100 & $99,43 a b$ & $3,75 a b$ & Médio \\
\hline IR 5206 & $97,10 \mathrm{ab}$ & $3,75 a b$ & Médio \\
\hline IR 5321 & $100,00 a$ & $3,75 a b$ & Médio \\
\hline IR 5336 & $98,86 a b$ & $3,75 a b$ & Médio \\
\hline Z 8452 & $98,83 \mathrm{ab}$ & $3,50 \mathrm{~b}$ & Baixo \\
\hline CMS 50 & $99,21 a b$ & $3,50 \mathrm{~b}$ & Baixo \\
\hline IR 4347 & $91,98 \mathrm{c}$ & $3,25 b$ & Baixo \\
\hline P 3210 & $97,16 a b$ & $3,25 b$ & Baixo \\
\hline$X L 380$ & $97,71 \mathrm{ab}$ & $3,00 \mathrm{~b}$ & Baixo \\
\hline Média & 97,73 & 4,06 & \\
\hline $\mathrm{CV}$ & $2.70 \%$ & $34,12 \%$ & \\
\hline
\end{tabular}

Médias seguidas da mesma letra na vertical não diferem entre si pelo teste de Duncan a $5 \%$ de probabilidade.

Refere-se a avaliações de campo.

Atribui-se à classificação das notas: de 1 a 3,5 = baixo; 3,6 a 5,0= médio e de 5,1 a $9=$ alto. As notas foram dadas independentemente, às duas linhas centrais, por dois observadores treinados.

\section{CONCLUSÕES}

1 - Os híbridos DINA 170, XL 380 e RA200 foram os que apresentaram melhor desempenho na produtividade, atingindo incrementos de $22,9 \%, 17,9 \%$ e $9,7 \%$, respectivamente, comparada à testemunha da 
região, BR 201, enquanto o híbrido IR 5206 sofreu redução de 24,4\%.

2 - Os híbridos avaliados apresentaram baixa ou média incidencia de Phaeosphaeria com exceção dada ao IR 4335, com alta incidência da doença.

3 - Portanto a escolha do híbrido adaptado mostrou-se ferramenta importante a custo zero para garantir aumento da produtividade em solo arenoso de cerrado, de baixa fertilidade, semeado tardiamente.

\section{AGRADECIMENTOS}

Aos Drs. Jonas Jager Fernandes e Júlio Cézar Viglioni Penna, da Universidade Federal de Uberlândia, pelas sugestões; à FUNDAP/UFU por ceder a área física, e à Rhodia Agro, pelo auxílio financeiro.

\section{REFERÊNCIAS BIBLIOGRÁFICAS}

COMISSÃO DE FERTILIDADE DO SOLO DO ESTADO DE MINAS GERIAIS, 1989. Recomendações para o Uso de Corretivos e Fertilizantes em Minas Gerais, IV Aproximação. Lavras, 176p.

EBERHART, S.A. \& RUSSEL, W.A., 1966. Stability Parameters for Comparing Varieties. Crop Science, v.6, n.1, p.36-40.

EMPRESA BRASILEIRA DE PESQUISA AGROPECUÁRIA EMBRAPA, 1979. Serviço Nacional de Levantamento e Conservação de Solos. Manual de Métodos de Análise de Solo. Rio de Janeiro. 80p. EMPRESA BRASILEIRA DE PESQUISA AGROPECUÁRIA EMBRAPA, 1982. Serviço Nacional de Levantamento e Conservação de Solos. Levantamento de Média Intensidade dos Solos e Avaliação da Aptidão Agrícola das Terras do Triângulo Mineiro. Rio de Janeiro. 526p. (Boletim Técnico, 1).

MAGALHÃES, P.C. \& E. PAIVA, 1993. Fisiologia da produção. In: CRUZ, J.C., MONTEIRO, J.A.; D.P.SANTANA; J.C. GARCIA; F.G.F.T.C. BAHIA; L.M.A SANS \& I.A. PEREIRA FILHO. Recomendações Técnicas para o Cultivo do Milho. Brasília: EMBRAPA, p.85-95. 
MACEDO, J. 1996. Produção de Alimentos: o potencial dos cerrados. Planaltina: EMBRAPA/CPAC, 33p. (Documentos, 59).

OLIVEIRA, M.A.S.; N.F. SAMPAIO \& F.M.P. VIANA, 1982. Avaliação de Cultivares de Milho em Rondônia, 81/82. Porto Velho: EMBRAPA/UPAE, 7p. (Comunicado Técnico, 21).

OLIVEIRA, M.N.A., 1992. Situação e Perspectiva do Milho na Região Sul e no Brasil. In: CONGRESSO NACIONAL DE MILHO E SORGO, 19. Porto Alegre: Conferências...EMBRAPA/CNPMS, 304p. PACCOLA-MEIRELLES, L.D.; W.F. MEIRELLES; E.P. CERVELLATI; C.S. MAKI; C.R. CASELA; F.T. FERNANDES \& A.S. FERREIRA, 1998. Caracterização Morfológica de Lesões da Mancha Foliar por phaeosphaeria e Avaliação da Incidência do Estágio Sexuado e Assexuado do Patógeno em Híbridos de Milho. In: CONGRESSO NACIONAL DE MILHO E SORGO, 22., Recife, 1998. Resumos expandidos... Recife: Empresa Pernambucana de Pesquisa Agrícola, EMBRAPA Milho e Sorgo, CD-Rom

PEGORARO, D.G.; J.F. BARBOSA NETO; E. VACARO; C.N. NUSS \& F.K. DALSOGLIO, 1998. Incidência da Mancha Foliar Causada pelo Fungo Phaeosphaeria maydis em Milho: Efeito de Épocas Semeadura e Doses de Nitrogênio. In: CONGRESSO NACIONAL DE MILHO E SORGO, 22., Recife, 1998. Resumos expandidos... Recife: Empresa Pernambucana de Pesquisa Agrícola, EMBRAPA Milho e Sorgo, CD-Rom

PEREIRA, F.I.A. \& J.C. CRUZ., 1993. Práticas culturais. In: CRUZ, J.C., MONTEIRO, J.A.; D.P.SANTANA; J.C. GARCIA; F.G.F.T.C. BAHIA; L.M.A SANS \& I.A. PEREIRA FILHO. Recomendações Téenicas para o Cultivo do Milho. Brasília: EMBRAPA, p.113-25. PIMENTEL-GOMES, F., 1990. Curso de Estatística Experimental. 13 ed., Piracicaba. 467p.

SILVA, P.R.F.; C. ARGENTA; R.C. CARMONA \& F. REZERA., 1996. Resposta de Genótipos de Milho à Densidade de Plantas, em Três Épocas de Semeadura. In: CONGRESSO NACIONAL DE MILHO E SORGO, 21., Londrina, 1996. Resumos... Londrina: Instituto Agronômico do Paraná, Associação Brasileira de Milho e Sorgo, p.204. 